\title{
Practical assessment on the run - iPads as an effective mobile and paperless tool in physical education and teaching
}

\author{
Roslyn Franklin* and Jubilee Smith \\ School of Education, Southern Cross University, East Lismore, Australia
}

(Received 25 March 2015; final version received 22 November 2015)

\begin{abstract}
This paper investigates the use of iPads in the assessment of predominantly second year Bachelor of Education (Primary/Early Childhood) pre-service teachers undertaking a physical education and health unit. Within this unit, practical assessment tasks are graded by tutors in a variety of indoor and outdoor settings. The main barriers for the lecturer or tutor for effective assessment in these contexts include limited time to assess and the provision of explicit feedback for large numbers of students, complex assessment procedures, overwhelming record-keeping and assessing students without distracting from the performance being presented. The purpose of this pilot study was to investigate whether incorporating mobile technologies such as iPads to access online rubrics within the Blackboard environment would enhance and simplify the assessment process. Results from the findings indicate that using iPads to access online rubrics was successful in streamlining the assessment process because it provided pre-service teachers with immediate and explicit feedback. In addition, tutors experienced a reduction in the amount of time required for the same workload by allowing quicker forms of feedback via the iPad dictation function. These outcomes have future implications and potential for mobile paperless assessment in other disciplines such as health, environmental science and engineering.
\end{abstract}

Keywords: mobile e-assessment; iPad; online rubrics; physical education; teacher education; pre-service teachers

\section{Introduction}

There is growing interest in the potential to extend the use of mobile technology in pre-service teacher education. Research indicates that replacing traditional and timeconsuming methods of written assessment and provision of feedback can significantly enhance the assessment process (Barnett et al. 2002; Bennett 2002; Buzzetto-More and Alade 2006; Byers 2001; Vendlinski and Stevens 2002). Gallo et al. (2013) argue that teaching large numbers of students, time restrictions, complex assessment procedures and associated record-keeping are the main barriers for effective assessment in physical education. However, little research currently supports the use of digital technology to improve the time-consuming written process of assessing practical performance tasks of pre-service teachers particularly in physical education. This pilot study aimed

*Corresponding author. Email: roslyn.franklin@scu.edu.au

Responsible Editor: Meg O’Reilly, Southern Cross University, Australia. 
to evaluate the potential of a mobile paperless assessment method using iPads and the effectiveness of online rubrics. Mobile devices such as iPads can be easily used in the assessment of physical education performance tasks that can link to the university Blackboard site where student grades are stored. The following questions framed the focus of the study:

(1) Whether the use of iPads with a dictation function in combination with online rubrics would improve the time-consuming written process of assessing pre-service teachers undertaking physical performance tasks by tutors.

(2) The relationship between the use of online rubrics and pre-service teacher's perceptions about assessment requirements and expectations and methods of receiving feedback.

To provide a context for the study, the next section examines the literature relating to various aspects of assessment in pre-service teacher education, especially the use of mobile technology and rubrics. The studies mentioned in this review have relevance to the current study as they predominantly examine rubric-based assessment in practical performance tasks.

\section{Literature review}

The majority of research relating to the use of mobile technology, such as iPads, for supporting learning has been directed towards primary and secondary education (Chen, Kao, and Sheum 2003; Rogers et al. 2005; Sharples, Corlett, and Westmancott 2002). Several studies have focused on technology use in teacher education (Blackwell et al. 2013; Herro, Kiger, and Owens 2013) and addressed issues regarding the use of mobile devices in learning and teaching and how the specific functionalities of these devices can be employed to support learning and assessment. However, there remains a paucity of research investigating the potential of using these devices specifically for practical assessment tasks such as those undertaken in physical education despite the fact that mobility is the distinctive feature of devices such as iPads.

Traditional paper and pencil methods to record the assessment of the practical performances of physical education students has proven cumbersome and timeconsuming. Byers (2001) confirms that interactive assessment such as technology-based data collection and analysis would promote dynamic feedback and enhance assessment 'on the fly' (p. 362). Research by McFarlane (2013) and Melhuish and Fallon (2010) confirms that the greatest affordance of an iPad for teaching and learning is its portability and its potential for real-time experiential learning. Therefore, the inclusion of mobile devices such as iPads as an easily accessible, mobile and paperless tool in practical assessment tasks could offer a potential solution. Patten, Sánchez, and Tangney (2006) identified seven functions by which a mobile device would serve educational requirements: administrative, referential, interactive, micro world, data collection, location aware and collaborative. The framework by Patten, Sánchez, and Tangney (2006) demonstrates that a variety of learning and potential assessment activities can be carried out using mobile devices. This functional framework of mobile device use and technology integration is used to evaluate the range of assessment activities carried out in this study alongside the evaluation of the benefits of using iPads in the assessment of practical tasks. These devices have the capacity to provide 
assessors with a tool that could conveniently record grades and deliver written, audio or video feedback by tutors using the dictation functionality of the iPad.

Several researchers have recognised that the use of different instructional, sport and physical education-related technologies and e-learning strategies would enhance the teaching of physical education (Kretschmann 2010; Macdonald and Hay 2010; Mohnsen 2008; Roblyer and Doering 2010). However, most studies about technology integration within physical education literature have focused on competency in device use (Kretschmann 2010; Mohnsen 2008; NASPE 2009; Russell 2007; Strand and Bender 2011; Woods et al. 2008). These devices have included monitoring systems such as digital video and cameras, heart rate monitors; active gaming devices; handheld devices such as mobile phones, video game consoles and sports-related software to demonstrate game play, tactics and provide motivation in teaching sports and physical education. Little research thus far has been conducted to indicate how the use of technology could improve the time-consuming written process of assessing students undertaking physical performance tasks.

The need to improve the practice of assessment generally in higher education has been well documented (Boud 2000; Maxwell 2010). Further research confirms the effect that assessment, including technology-based assessment, has on supporting and extending student learning (Earl 2003; Kirkwood and Price 2008; Rust 2002). An extensive review of literature relating to the use of assessment rubrics in higher education by Reddy and Andrade (2010) identifies the link between rubric use, increased student achievement and improved academic performance. The review highlights research by Powell (2001), Reitmeier, Svendsen, and Vrchota (2004), Andrade and Du (2005) and Schneider (2006) that examined student and instructor perceptions about rubric use. The findings from these studies conclude that students generally respond positively to rubric use. Conversely, two other studies (Bolton 2006; Parkes 2010) indicated a noted resistance by university instructors to incorporate rubrics as an assessment tool. One possible reason for this view, as noted by Hafner and Hafner (2003), is that rubric development requires a significant amount of time and effort on the part of the tutor or instructor. Conflicting results about the effectiveness of rubrics on student performance in studies by Petkov and Petkova (2006), Reitmeier, Svendsen, and Vrchota (2004) and Green and Bowser (2006) also confirm the importance of clarity and appropriateness of language in the development of effective assessment rubrics. In addition, Reddy and Andrade (2010) conclude that:

Important aspects of validity have not yet been addressed at all, including the need to establish the alignment between the criteria on the rubric and the content or subject being assessed (content validity); the facets of the intended construct being evaluated (construct validity); and the appropriateness of generalisations to other, related activities (criterion validity) (p. 445).

While validity and reliability of the rubrics used are not the focus of this study, this comment highlights a need for more research in the area of effective online assessment rubric development, particularly in the assessment of physical education. Several researchers (Andrade and Du 2005; Bolton 2006; Maxwell 2010; Parkes 2010; Shaw 2014) identified the key tenets for the effective use of rubrics for assessment in higher education, particularly in performance assessment, as being to: (1) clarify the assessment task; (2) enable regulation of planning of assignments; (3) produce work of better quality; (4) increase student confidence in undertaking the assessment task; 
(5) provide clear descriptions at each level of performance; (6) provide explicit learning outcomes and (7) make grading fair and transparent. Other research highlights the effectiveness and efficiency of utilising computer-assisted grading rubrics compared with other grading methods (Campbell 2005; Ahoniemi and Karavirta 2009; Gardner, Sheridan, and Andreas 2012; Heinrich et al. 2009). Further studies (Brown 2005; Orell 2006; Stefani 2004-2005) emphasise the necessity to include useful, effective and timely feedback and assert that using rubrics is a vital aspect of teaching and assessing should be included in current teaching practice. In addition, research (Ally, Grimus, and Ebner 2014; Rosenthal and Eliason 2015) highlights the need for lecturers in higher education to model best pedagogy and practice of ICT (Information Communication Technology) integration to enable pre-service teachers to develop knowledge and skills that will transfer into their teaching setting. Shaw (2014) confirms this view and suggests that when the faculty employ rubrics to document student learning, it provides an opportunity to model pedagogical practice. All of the factors mentioned not only have implications for modifications to the rubrics developed for this study but also, in general, for future rubric awareness and development in teacher education.

\section{Methodology}

The methodology underpinning this study is action research. Action research is a flexible spiral process to promote change and improve practice (Cole and Knowles 2000; Cousin 2009; Hansen and Nalder-Godfrey 2004; Johnson 1993; Kemmis and McTaggart 2005; Sagor 2000; Souto-Manning 2012; Tinning 1992). It consists of a cyclical process based on four phases: (1) problem identification, (2) taking initial action, (3) data collection and analysis and (4) reflection and data-driven action before beginning the spiral again. It is the intention of this study to reflect on and disseminate results to improve and update current practices in assessment, particularly in units such as physical education, where practical tasks are prevalent. In order to gain a richer understanding about the aim and purpose of this study, the next section describes the research site and context.

\section{Project overview}

This pilot study was part of a year-long university learning and teaching grant that investigated the use of iPads in the assessment of a mixed group of second, third and fourth year pre-service teachers undertaking a Personal Development, Health and Physical Education unit (PDHPE) within the Bachelor of Education (Primary/Early Childhood) program. This study took place at three campuses of a regional Australian university. The university has a long history of distance education, maintains a strong ICT focus and has a centrally supported e-learning management system called Blackboard. This system, widely used throughout the Australian and international higher education community, is an easy to use browser-based content learning management system (LMS) enabling online collaboration as well as access to study materials and resources. The majority of study units have an associated Blackboard site and the School of Education uses these sites to present unit materials and provide students with feedback and grades.

Two practical tasks, a Health 'Show and Tell' presentation in a classroom and a physical education micro-teaching assessment task were used to trial the use of iPads 
and its audio dictation function in the unit assessment. Practical tasks in this study were assessed by five tutors across three campuses and took place in either a classroom, a gymnasium or on an oval creating a number of practical challenges for the provision of student feedback. The main barrier to assessment in this context and in these types of locations is to assess the pre-service teacher's performance in a timeefficient manner. Therefore, this project aims to investigate the relationship between the use of iPads and online rubrics as part of the assessment process.

\section{Participants}

The study focused on the practical assessment of 250 pre-service teachers undertaking a PDHPE unit. Out of the pre-service teacher cohort: $58 \%$ were 2 nd year students, $15 \%$ were 3 rd year and $12 \%$ were 4 th year students. The age range of the participants was between 18 and 54 years, with $72 \%$ female and 28\% male. A random sample of pre-service teachers were given a survey to complete annonymously and details are attached in Appendix 1. Five tutors, who had at least 5 years tutoring experience and whose average age was 44.6 years, were also involved in the study across the three SCU campuses and all were briefed about the purpose of the pilot and provided with an Apple iPad (4th generation) with Wi-Fi capability, earphones and microphone. All tutors were relatively confident in the use of technology but not so familiar with iPads and how to connect to the internal Blackboard system. All tutors were therefore provided with introductory training on how to use the iPads and the internal Blackboard system rubric tool. The individual rubric was devised offline and then built on the Blackboard shell using the rubric tool.

\section{Data collection and analysis}

To investigate the potential of using iPads in practical physical education and health assessment tasks, the study was conducted in four phases: Phase 1 - Problem identification, Phase 2 - Pilot iPad trial, Phase 3 - Survey and semi-structured interviews, and Phase 4 - Reflection and discussion of results.

In Phase one, the problem identification stage of this action research study, a consultative meeting was organised with the Digital Learning and Teaching team to discuss the rubric tool located on the university's Blackboard site and its suitability for mobile assessment. It was deemed that the rubric could be translated into a digital format and made available for pre-service teachers on the university Blackboard site. As a result, an online rubric was developed for each of the two targeted assessment tasks: a physical education micro-teach and a Health 'Show and Tell' presentation. In addition, pre-service teachers were provided with a copy of the rubric at the beginning of the unit, which included performance-level descriptors to guide their assessment preparation. A copy of the micro-teach rubric is attached as an example in Appendix 2. Tutors marking the practical assessment task ticked the appropriate rubric criteria boxes online using the iPad and provided additional feedback in the comments box by using the dictation function and microphone. The basic features of rubric marking online enabled the tutor to mark electronically, select the appropriate level descriptors associated with each criterion relevant to each preservice teacher's level of achievement and provide electronic feedback either typed or dictated. The online rubric functionality then automatically calculated the marks allocated by the tutor and sent them to each individual pre-service teacher's grade 
repository (gradebook). Apart from having access to both grade and online feedback, pre-service teachers also received brief verbal feedback immediately after their assessment.

During the trial phase, the tutors received instructions and training on how to use the iPad and the rubrics on Blackboard. A hard copy (paper) version of the rubric was also printed in the initial trial to ensure that if the technology failed or was not deemed the preferred method by the tutor, they had a record of each individual's attempt at the task. Pre-service teachers were all given a copy of the rubric well before the practical assessment task during tutorials on campus. In the initial stages of the project, the authors trialled the applications and Apps, such as Garageband, were explored to compare and determine how to provide appropriate audio feedback on the iPad.

Phase two consisted of a trial to use the iPads and online rubrics to assess the practical delivery of a physical education micro-teaching episode and a Health 'Show and Tell' presentation by 250 pre-service teachers. The 'Show and Tell' presentations consisted of each pre-service teacher presenting a health strategy to their peer group. This was scheduled across weeks 3-11 of the semester and took place in a tutorial classroom. In the physical education micro-teaching task, students were required to teach a skill utilising a Teaching Games for Understanding (TGfU) approach to a group of peers. Their performance was assessed individually either at campus-specific gymnasiums or on an oval depending on the skill/game being taught. Internet access was tested in each location prior to use to ensure that the iPads could be used in the process of assessment of both tasks. After the first week of assessment, all tutors consulted with each other to moderate the grades being allocated to students and to determine any issues found when using the iPad.

Phase three consisted of a survey given to pre-service teachers to determine their perceptions about the use of online rubrics and quality of feedback provided after their practical assessment tasks. The survey consisted of five questions related to: access to the marking rubric prior assessment; clarification of expectations, rubric and comment feedback; comparison with receiving only a final grade and overall feedback experience. The pre-service teachers completed the survey anonymously at the end of the assessment period after they had received their results and feedback.

In addition, semi-structured interviews regarding the use of iPads were conducted with the five tutors. The following interview questions guided the discussion:

(1) What are the benefits and challenges in using iPads as an assessment tool?

(2) What impact did the rubrics for online marking have on the assessment process when evaluating practical assessment tasks for both pre-service teachers and tutors?

Responses to the study research questions are discussed in the following section.

\section{Results and discussion}

Phase four, which involves reflection and data-driven analysis, outlines the results of the pilot study in terms of the (1) range of activities that the iPads were able to support in the assessment process; (2) benefits; and (3) challenges and issues encountered in the use of both iPads and online rubrics. To analyse the data, a framework was employed that had been used by Fabian and McLean (2014) to identify and 
assess the benefits and pitfalls when using mobile devices in learning and teaching activities. This framework, originally developed by Patten, Sánchez, and Tangney (2006), analysed handheld applications in relation to their application function and pedagogical underpinning. In this study, the framework by Patten, Sánchez, and Tangney (2006) was used to map the categories of application and highlight the useful functions undertaken and possible pedagogical implications in the process of assessment using iPads as shown in Table 1.

Based on this framework, it is evident that the predominant purpose in the use of iPads for assessment was administrative, which included its interactivity and data collection function. However, as the data suggest, the formulation of explicit rubrics on Blackboard also allowed tutors to evaluate pre-service teachers' performance on site and facilitated learning and engagement in the task criteria prior to the assessment period. In addition, the dictation function and mobile availability of the iPad offered tutors a more time-efficient method of providing feedback than the original paperbased feedback for the task. There were, however, limitations in the use of iPads, and these will be clarified in subsequent sections.

\section{Benefits}

Analysis of data from the student survey and semi-structured interviews with tutors revealed that the use of iPads and online rubrics significantly improved the efficiency and quality of assessment procedures in the health and physical education unit assessment tasks. Based on the findings, the most outstanding benefit for pre-service teachers was the immediacy and quality of feedback. The original thought was that they would receive their performance feedback immediately. However, a short time delay between the feedback process and the release of the feedback results for each assessment was deemed necessary to undertake a process of moderation across three campuses. The delay in feedback release was to ensure that all grades awarded were consistent. Overall, pre-service teachers were satisfied with this explanation and were still impressed by the quick return of results and feedback (how long?). In addition, at the end of their micro-teaching assessment, a few minutes were spent with each pre-service teacher to personally provide immediate feedback and discuss their performance. This allowed the students and the tutor to come to a common understanding and consensus about the strengths and weaknesses of the performance before the final online grade and comment was released. Therefore, the provision of multi-faceted mode of assessment feedback in this pilot study afforded pre-service teachers the opportunity to reflect on the quality of their work and areas for improvement. This aligns with research by Lombardi $(2008$, p. 4) who confirms that 'learners want to know the criteria by which they will be judged, but they also want processes in place to help them improve and develop, guided by clear, practical, and specific feedback'.

The first question in the survey was to ascertain how many pre-service teachers actually accessed the rubric before their practical assessment. An analytic rubric was provided for each assessment task and was explained in detail to them at the beginning of the unit. A video recording was also made about the expectations and requirements of each task to increase pre-service teacher understanding. Of the 58 responses, only one pre-service teacher did not access the rubric. The second question sought to find out the 'extent to which the rubric clarified the assessment requirement?' The majority of pre-service teachers found that the rubric helped to clarify each assessment task and set a realistic idea of what was required. The following responses to the third question 
Table 1. Assessment activities mapped into Patten, Sánchez and Tangney (2006) functional pedagogical framework.

\begin{tabular}{|c|c|c|c|c|c|c|c|}
\hline Functional framework used iPad to: & Administration & Referential & Interactive & Microworld & $\begin{array}{l}\text { Data } \\
\text { collection }\end{array}$ & $\begin{array}{l}\text { Location } \\
\text { aware }\end{array}$ & Collaborative \\
\hline Wirelessly connect to Blackboard via the Internet & $\checkmark$ & & & & & $\checkmark$ & \\
\hline $\begin{array}{l}\text { Carry out assessment inside and outside the } \\
\text { classroom }\end{array}$ & $\checkmark$ & & & & $\checkmark$ & $\checkmark$ & \\
\hline Use rubric tool available in Blackboard & $\checkmark$ & & $\checkmark$ & & $\checkmark$ & $\checkmark$ & \\
\hline $\begin{array}{l}\text { Type in assessment feedback directly to } \\
\text { Blackboard }\end{array}$ & $\sqrt{ }$ & & $\checkmark$ & & $\checkmark$ & $\checkmark$ & $\checkmark$ \\
\hline $\begin{array}{l}\text { Dictate assessment feedback directly to } \\
\text { Blackboard }\end{array}$ & $\checkmark$ & & $\checkmark$ & & $\checkmark$ & $\checkmark$ & $\sqrt{ }$ \\
\hline Grade students in practical assessment tasks & $\checkmark$ & & $\checkmark$ & & $\checkmark$ & $\sqrt{ }$ & $\sqrt{ }$ \\
\hline Provide timely feedback & $\checkmark$ & & $\sqrt{ }$ & & & & $\sqrt{ }$ \\
\hline
\end{tabular}


in the survey highlighted their perceptions about the effectiveness of receiving rubric and specific written feedback:

It is very reassuring to receive additional feedback and suggestions for future assessment. (BEd Pre-service Teacher A)

Feedback is very useful to allow me to modify my approaches to teaching. (BEd Pre-service Teacher B)

The final question required pre-service teachers to comment on their experience regarding the method and timeliness of their assessment feedback. Most of them expressed a preference for the use of rubrics as the feedback guided their future learning (Reddy and Andrade 2009). In addition, the timeliness of results and quality of feedback was appreciated and gave meaning and understanding to the assessor's grading of the assessment tasks. These pre-service teacher comments align with the framework of principles and standards for effective assessment practices developed by Gardner et al. (2008, p. 20). Gardner et al. (2008) argue that knowing and using the criteria for the standard of work required demonstrates to students what they should be aiming for and provides them with evidence of how judgements about their learning are made. The majority of pre-service teachers who participated in this project appreciated having an explicit rubric to guide preparation for their assessment task. Research by Reddy and Andrade (2009) confirmed that students who are provided with rubrics in advance to guide their work generally have a deeper understanding of the assessment task, resulting in higher levels of achievement. This is only applicable where students take the time to thoroughly read and actively use the rubric (Jonsson 2010; Jonsson and Svingby 2007). Pre-service teachers' responses also indicated that the rubrics provided made the assessment task transparent and clearly outlined the criteria and expectations by which they were to be judged. From a tutor's perspective, the rubric provided an opportunity to reflect on the criteria for the task/s and design appropriate teaching and learning activities that would assist and lead into the assessment tasks for the unit content (health and physical education).

The analysis of data from semi-structured interviews with tutors revealed that time was a key issue when marking practical assessment tasks. All tutors expressed satisfaction with using iPads in the assessment process but were more impressed by the time-efficient use of the computer-assisted grading rubrics. Using mobile devices in this way compared favourably with the previous paper-based feedback system, as the latter took more time and required managing paper and pen while simultaneously attempting to pay attention to the practical assessment task. Gardner, Sheridan, and Andreas (2012) argue that 'time is the most challenging factor when marking' and divides time into an allocation for 'administrative tasks (marking per se) and time spent on engaging with student's work and providing individual feedback' (p. 392). Several other researchers (Ahoniemi and Karavirta 2009; Anglin et al. 2008; Milne, Heinrich, and Morrison 2008) confirm that e-tools provide more time to provide individual feedback reduces paper usage and generally improve the manual grading process. Tutors in this study indicated several positive reasons for using computerassisted rubrics as shown in the following responses:

I prefer to provide feedback quickly - this method did. (Tutor A)

Workload cut down dramatically. (Tutor B)

Saved time manually up-loading student's individual grades into the unit's Grade Centre.

(Tutor C) 
Overall the strength of this tool lies in the fact that once the online rubric was completed by the tutor, the results and the feedback were immediately available for the students to access. (Tutor D)

The results suggest that the combined use of iPads and rubrics in the assessment process significantly reduced the time required and management of multiple paper items (the workload) by tutors and provided pre-service teachers with valuable and timely feedback. However, the process was not without issues and challenges and these are discussed in detail in the next section.

\section{Challenges and issues}

Whilst the overall use of iPads and rubrics could be deemed as successful, judging from the positive response from the pre-service teachers and tutors, the use of the iPads in the assessment process was not totally free of problems. The challenges have been grouped into technical and assessment issues.

\section{Technical issues}

(1) Access and Maintaining Connectivity to the Internet - This aspect was mentioned as challenging when assessing the physical education micro-teach at an off-campus gymnasium. Two tutors identified the following areas as challenging in this context: (1) Difficulty to access the Internet via Wi-Fi at off-campus sites; (2) Difficulty to maintain connectivity; (3) Use of personal iPhone hotspot access to maintain connectivity. All tutors commented that access to Internet via $\mathrm{Wi}-\mathrm{Fi}$ in most cases was problematic and highly unpredictable. This resulted in the need to purchase and pay for personal 'hotspots' at the tutor's expense.

(2) Voice recognition on iPad - Tutors found that they needed time to ensure the proper functioning of the voice recognition function (dictation), so that the device recorded the comments without any error. Considerable editing was required in the first trial using this method.

(3) iPad screen capacity - An internal issue with Blackboard was that the screen visibility of the iPads only allowed for a small number of student names to be accessed on the screen. In order to overcome this issue, pre-service teachers were to be placed into assessment groups of up to 25 . In addition, there were challenges with the allocation of the columns for the assessment feedback. The Blackboard site required some preparation of the columns and group allocations before use to overcome this issue.

\section{Assessment issues}

(1) Time delay caused by moderation processes - As tutors needed to consult with other tutors and moderate across groups, the feedback was delayed by a couple of days. This was outweighed by the fact that the use of the voice recognition was both time-efficient and effective in the gymnasium and the oval setting as opposed to the use of paper feedback. 
(2) Complexity of feedback in some cases - One tutor reported that in the case of pre-service teachers who did not perform well in the micro-teaching activity, there was a need to refer to their original lesson plan (on another part of the Blackboard submission system) in order to provide additional feedback. This also caused a short delay in the release of the final student feedback for the task.

(3) Use of microphone to record the pre-service teachers' feedback - The dictation function on the iPad was not suitable in a group setting, such as in the Health 'Show and Tell' assessment, where comments could be overheard by other pre-service teachers.

Based on the findings, tutors were able to identify important benefits for the use of iPads in practical assessment tasks that compensated for the occasional lack of access to Internet or maintenance of connectivity. The electronic interactive rubric used on Blackboard proved to be time-efficient and an effective way of assessing students practical performance with the comment section located at the end of the rubric especially useful for additional personalised observations or statements. This resulted in what was considered to be better quality feedback because the process of assessment was quicker which allowed the tutor more time to process the performance evaluated. The benefits seemed to offset the issues and problems, and tutors found that generally they were able to complete the task in less time once the issues were identified. The time-saving element of the use of the iPads was substantial as was the reduction in the use of paper to provide feedback. The use of the online rubric saved time in terms of supporting workflow efficiency and assisting in the delivery of initial criteria-specific feedback, and tutors were able to provide additional in-depth quality comments.

The following were the key areas identified as positive about the mobile assessment strategy adopted in the project:

- Time saved for paper printing and handing out to pre-service teachers.

- Time saved to write/prepare and upload the feedback as this was instantly online and could be released once approved - no double handling of the paper.

- Feedback was more directly available (once the assessment feedback was moderated).

- Feedback was more individualised (voice recognition of the tutor's words) and more detailed piece of feedback.

- Rubrics provided clarity of expectations and task performance for tutors and pre-service teachers.

- Pre-service teacher feedback could be linked to individual task criteria and provided by the tutor in a clear and consistent manner.

\section{Conclusions}

This paper draws attention to the significant benefits that the use of technology such as iPads and computer-assisted grading rubrics can offer in assessing performancebased tasks in university courses such as health and physical education. The results emphasise the potential of rubrics to help pre-service teachers understand the expectations and targets for their learning and the standard requirements of a 
particular assignment task. In addition, rubrics can provide them with an opportunity to make dependable judgements about their own work that can inform reflection, revision and improvement. The paper also highlights the possible limitations of the technology imposed by lack of connectivity and capacity of the iPad itself as well as the lack of privacy when providing audio feedback in the classroom context. As an added initiative, the results of this pilot study in the form of information and instructions for iPad and online rubric use have been developed and disseminated to other faculties within the university who may have similar performance-based assessment.

This research has implications for the way universities develop consistent and effective methods of assessment and e-learning resources to assist lecturers and tutors in the process. This study raises important considerations for academics about the use of technology and in particular iPads for learning and teaching. The literature highlights the expanding use of iPads and other mobile devices in education from K-12 through to higher education (Byers 2001; Miller 2012; Parkes 2010; Patten, Sánchez, and Tangney 2006; Peluso 2012). One of the goals from the Melbourne Declaration on the Educational Goals for Young Australians (MCEETYA 2008) emphasises the critical need for young people to develop competencies in ICT and specifically in the use of a variety of devices to become creative and productive users of that technology. This has implications for teacher educators who must be willing and able to model exemplary assessment tasks and feedback to ensure that pre-service teachers have the capability and knowledge of technology integration for the 21st Century classroom. The use of iPads and other mobile technology may support this aim by assisting teacher educators to model exemplary ICT integration. An aspect worth consideration is that the investment in technology such as iPads is costly and will undoubtedly be replaced by other technological tools in the future. It is also evident that with the increase in mobile technology use, we as teacher educators should be addressing how we are using devices such as iPads to inform and shape the preparation of a new generation of teachers.

\section{References}

Ahoniemi, T. \& Karavirta, V. (2009) 'Analyzing the use of a rubric-based grading tool', 14th Annual ACM SIGCSE Conference on Innovation and Technology in Computer Science Education, ACM, Paris, France, pp. 333-337.

Ally, M., Grimus, M. \& Ebner, M. (2014) 'Preparing teachers for mobile world to improve access to education', Prospects, vol. 44, no. 1, pp. 43-59.

Andrade, H. \& Du, Y. (2005) 'Student perspectives on rubric-referenced assessment', Practical Assessment, Research \& Evaluation, vol. 10, no. 5, pp. 1-11.

Anglin, L., et al., (2008) 'Improving the efficiency and effectiveness of grading through the use of computer-assisted grading rubrics', Decision Sciences Journal of Innovative Education, vol. 6 , no. 1 , pp. 51-73.

Barnett, M., et al., (2002) 'Using emerging technologies to help bridge the gap between university theory and classroom practice: challenges and successes', School Science and Mathematics, vol. 102, no. 6, pp. 299-313.

Bennett, R. E. (2002) 'Inexorable and inevitable: The continuing story of technology and assessment', The Journal of Technology, Learning, and Assessment, vol. 1, no. 1, pp. 1-22.

Blackwell, C. K., et al., (2013) 'Adoption and use of technology in early education: the interplay of extrinsic barriers and teacher attitudes', Computers \& Education, vol. 69, pp. 310-319.

Bolton, C. F. (2006) 'Rubrics and adult learners: andragogy and assessment', Assessment Update, vol. 18, no. 3, pp. 5-6.

Boud, D. (2000) 'Sustainable assessment: rethinking assessment for the learning society', Studies in Continuing Education, vol. 22, pp. 151-167. 
Brown, S. (2005) 'Assessment for learning', Learning and Teaching in Higher Education, vol. 1, no. 1, pp. 81-89.

Buzzetto-More, N. A. \& Alade, A. J. (2006) 'Best practices in e-assessment', Journal of Technology Education, vol. 5, pp. 251-269.

Byers, C. (2001) 'Interactive assessment: an approach to teaching and learning', Journal of Interactive Learning Research, vol. 12, no. 4, pp. 359-374.

Campbell, A. (2005) 'Application of ICT - and rubrics to the assessment process where professional judgement is involved: the features of an e-marking tool', Assessment \& Evaluation in Higher Education, vol. 30, no. 5, pp. 529-537.

Chen, Y., Kao, T. \& Sheum, J. (2003) 'A mobile learning system for scaffolding bird watching learning', Computer-Assisted Learning, vol. 19, pp. 347-359.

Cole, A. L. \& Knowles, J. G. (2000) Researching Teaching: exploring Teacher Development through Reflexive Inquiry, Allyn \& Bacon, Boston, MA.

Cousin, G. (2009) Researching Learning in Higher Education, Routledge, Abingdon.

Earl, L. (2003) Assessment as Learning: Using Classroom Assessment to Maximise Student Learning, Corwin Press, Thousand Oaks, CA.

Fabian, K. \& MacLean, D. (2014) 'Keep taking the tablets? Assessing the use of tablet devices in learning and teaching activities in further education', Research in Learning Technology, vol. 22, [online] Available at: http://www.researchinlearningtechnology.net/index.php/rlt/ article/view/22648

Gallo, A. M., et al. (2013) 'Assessment benefits and barriers', Journal of Physical Education, Recreation \& Dance, vol. 77, no. 8, pp. 46-50.

Gardner, J., et al., (2008) Changing Assessment Practice: Process, Principles and Practice, [online] Available at: http://www.nuffieldfoundation.org/sites/default/files/JG Changing Assment Practice Final Final\%281\%29.pdf

Gardner, L., Sheridan, D. \& Andreas, N. (2012) 'Rubric marking "Out of the box": saving time and adding value to teaching and learning', Journal of Interactive Learning Research, vol. 13, no. 2, pp. 39-47.

Green, R. \& Bowser, M. (2006) 'Observations from the field: sharing a literature review Rubric', Journal of Library Administration, vol. 45, no. 1-2, pp. 185-202.

Hafner, J. C. \& Hafner P. M. (2003) 'Quantitative analysis of the rubric as an assessment tool: an empirical study of student peer-group rating', International Journal of Science Education, vol. 25, no. 12, pp. 1509-1528.

Hansen, J. M. \& Nalder-Godfrey, N. (2004) 'The power of action research, technology and teacher education', Computers in Schools, vol. 21, no. 1/2, pp. 43-57.

Heinrich, E., et al., (2009) 'Recommendations for the use of e-tools for improvements around assignment marking quality', Assessment \& Evaluation in Higher Education, vol. 34, no. 4, pp. $469-479$.

Herro, D., Kiger, D. \& Owens, C. (2013) 'Mobile technology: case-based suggestions for classroom integration and teacher educators', Journal of Digital Learning in Teacher Education, vol. 30, no. 1, pp. 30-40.

Johnson, B. (1993) Teacher as Researcher. Clearinghouse on Teacher Education, Washington, DC. (ERIC Document Reproduction Service No. ED 355205).

Jonsson, A. (2010) 'The use of transparency in the "Interactive examination" for student teachers', Assessment in Education: Principles, Policy \& Practice, vol. 17, no. 2, pp. 183-197.

Jonsson, A. \& Svingby, G. (2007) 'The use of scoring rubrics: reliability, validity and educational consequences', Educational Research Review, vol. 2, pp. 130-144.

Kemmis, S. \& McTaggart, R. (2005) 'Participatory action research: communicative action and the public sphere', in The Sage Handbook of Qualitative Research, eds. N. K. Denzin, K. Norman \& Y. S. Lincoln, Sage, London, pp. 271-330.

Kirkwood, A. \& Price, L. (2008) 'Assessment and student learning: a fundamental relationship and the role of information and communication technologies', Open Learning: The Journal of Open and Distance Learning, vol. 23, p. 516.

Kretschmann, R. (2010) 'Physical education 2.0', in Looking toward the Future of TechnologyEnhanced Education: Ubiquitous Learning and the Digital Native, eds. M. Ebner \& M. Schiefner, IGI Global, Hershey, PA, pp. 432-454.

Lombardi, M. M. (2008) 'Making the grade: the role of assessment in authentic learning', [online], Available at: http://net.educause.edu/ir/library/pdf/eli3019.pdf 


\section{R. Franklin and J. Smith}

Macdonald, D. \& Hay, P. (2010) 'Health \& physical education as/and technology: an Australian perspective', Presented at Global Forum for Physical Education Pedagogy, Iowa, USA, [online] Available at: http://www.globalpeforumgc.org/sites/default/files/ presentations/Macdonald-Hay.pdf

Maxwell, S. (2010) 'Good, better, best: the use of rubrics for graded assessment', Teacher: The National Education Magazine, Jun/Jul., pp. 34-36, 38, [online] Available at: http://search.informit.com.au/documentSummary; $\mathrm{dn}=131493859783138 ; \mathrm{res}=$ IELHSS

McFarlane, C. (2013) 'iPads and their potential to revolutionise learning', Proceedings from the World Conference on Educational Multimedia, Hypermedia and Telecommunications, [online] Available at: http://www.editlib.org/p/112193/

Melhuish, K. \& Fallon, G. (2010) 'Looking to the future: M-learning with the iPad', Computers in New Zealand Schools: Learning, Leading, Technology, vol. 22, no. 3, pp. 1-16.

Miller, W. (2012) 'iTeaching and learning: collegiate instruction incorporating mobile tablets', Library Technology Reports, vol. 48, no. 8, pp. 54-59.

Milne, J., Heinrich, E. \& Morrison, D. (2008) 'Technological support for assignment assessment: a New Zealand higher education survey', Australasian Journal of Educational Technology, vol. 24, no. 5, pp. 487-504.

Ministerial Council on Education, Employment, Training \& Youth Affairs. (2008) Melbourne Declaration on Educational Goals for Young Australians, [online] Available at: http://www. curriculum.edu.au/verve/_resources/national_declaration_on_the_educational_goals_for_ young_australians.pdf

Mohnsen, B. (2008) Using Technology in Physical Education. 6th edn, Bonnie's Fitware, Cerritos, CA.

NASPE (National Association for Sport and Physical Education). (2009) Appropriate Use of Instructional Technology in Physical Education. Position Statement. NASPE, Reston, VA, [online] Available at: http://www.shapeamerica.org/advocacy/positionstatements/pe/ loader.cfm?csModule $=$ security/getfile\&pageid $=4679$

Orell, J. (2006) 'Feedback on learning achievement: rhetoric and reality', Teaching in Higher Education, vol. 11, no. 4, pp. 441-456.

Parkes, K. A. (2010) 'Performance assessment: lessons from performers', International Journal of Teaching and Learning in Higher Education, vol. 22, no. 1, pp. 98-106.

Patten, B., Sánchez, I. A. \& Tangney, B. (2006) 'Designing collaborative, constructionist and contextual applications for handheld devices', Computers and Education, vol. 46, no. 3, pp. 294-308.

Peluso, D. (2012) 'The fast-paced iPad revolution: can educators stay up to date and relevant about these ubiquitous devices? The British Journal of Educational Technology, vol. 43, no. 4 , pp. $125-127$.

Petkov, D. \& Petkova, O. (2006) 'Development of scoring rubrics for IS projects as an assessment tool', Issues in Informing Science and Information Technology, vol. 3, pp. $499-510$.

Powell, T. A. (2001) Improving Assessment and Evaluation Methods in Film and Television Production Courses, PhD Dissertation, Capella University, UMI No. 3034481.

Reddy, Y. M. \& Andrade, H. (2010) 'A review of rubric use in higher education', Assessment \& Evaluation in Higher Education, vol. 35, no. 4, pp. 435-448.

Reitmeier, C. A., Svendsen, L. K. \& Vrchota, D. A. (2004) 'Improving oral communication skills of students in food science courses', Journal of Food Science Education, vol. 3, pp. $15-20$.

Roblyer, M. D. \& Doering, A. H. (2010) Integrating Educational Technology into Teaching. 5 th ed, Pearson, London.

Rogers, Y., et al., (2005) 'Ubi-learning integrating indoor and outdoor learning experiences', Communications of the ACM, vol. 48, no. 1, pp. 55-59.

Rosenthal, M. B. \& Eliason, S. K. (2015) "II Have an iPad. Now What?" Using mobile devices in university physical education programs', Journal of Physical Education', Recreation \& Dance, vol. 86, no. 6, pp. 34-39.

Russell, W. (2007) 'Physical educators' perceptions and attitudes toward interactive video game technology within the physical education curriculum', Missouri Journal of Health, Physical Education', Recreation and Dance, vol. 17, pp. 76-89. 
Rust, C. (2002) 'The impact of assessment on student learning', Active Learning in Higher Education, vol. 3, pp. 145-158.

Sagor, R. (2000) Guiding School Improvement with Action Research, Association for Supervision and Curriculum Development, Alexandria, VA.

Schneider, J. F. (2006) 'Rubrics for teacher education in community college', The Community College Enterprise, vol. 12, no. 1, pp. 39-55.

Sharples, M., Corlett, D. \& Westmancott, O. (2002) 'The design and implementation of a mobile learning resource', Personal and Ubiquitous computing, vol. 6, pp. 220-234.

Shaw, G. F. (2014) 'Introducing rubrics to physical education teacher candidates', Journal of Physical Education, Recreation \& Dance, vol. 85, no. 6, pp. 31-37.

Souta-Manning, M. (2012) 'Teacher action research in teacher education: Teacher as researcher', Childhood Education, vol. 88, no. 1, pp. 54-66.

Stefani, L. (2004) 'Assessment of student learning: promoting a scholarly approach', Learning and Teaching in Higher Education, vol. 1, no. 1, pp. 51-66.

Strand, B. \& Bender, V. (2011) 'Knowledge and use of appropriate instructional strategies by physical education teachers', Physical Educator, vol. 68, no. 1, pp. 2-17.

Tinning, R. (1992) 'Action research as epistemology and practice: towards transformative educational practice in physical education', in Research in Physical Education and Sport: Exploring Alternative Visions, ed. A. C. Sparkes, The Farmer Press, London, pp. $188-210$.

Vendlinski, T. \& Stevens, R. (2002) 'Assessing student problem-solving skills with complex computer based tasks', Journal of Technology, Learning, and Assessment, vol. 1, no. 3, pp. 3-18.

Woods, M. L., et al., (2008) 'Physical educators' technology competencies and usage', Physical Educator, vol. 65, no. 2, pp. 82-99. 


\section{Appendix 1}

Student Survey - Practical Assessment on the Run

Personal information:

Male or Female (please circle)

Age:

In what year of your studies are you currently?

$1^{\text {st }} 2^{\text {nd }} 3^{\text {rd }} 4^{\text {th }}$ other

Survey questions:

These questions are intended to assist us to understand how useful you found the online marking rubric for the assessment task in this unit:

(1) Did you access the marking rubric prior to completing the presentation?

a. Health: Show and Tell presentation: yes/no

b. Physical Education: Micro-teach: yes/no

(2) To what extent did the rubric clarify the assessment requirements and expectations? very useful somewhat useful useful not useful

(3) Did you find receiving the detailed rubric and the comment feedback useful? very useful somewhat useful useful not useful

Brief comment:

(4) How useful was this compared to only receiving only a final grade for the task? very useful somewhat useful useful not useful

Brief comment:

(5) Comment on your experience regarding this type of assessment feedback (rubric detail/immediacy of return and other comments where relevant):

Thank you for completing this survey. 
Appendix 2 - TGfU Micro-Teach Assessment Rubric

Student name:

Student ID:

You will be required to demonstrate in your lesson plan the pedagogical principles covered in practical sessions. In addition, you need to plan for, and use, questioning that promotes higher order thinking.

Marking criteria will demonstrate your ability and capacity to:

Your micro teach will

be assessed on your

ability and capacity to:

Demonstrate an ability

to provide

appropriate

objectives that are

suitable for the

specified age group

\& appropriate warm-

up

\section{5 marks}

\section{Demonstrate the} ability to effectively

plan for the key

pedagogical

principles of a TGfU

approach

5 marks

Outstanding

Well-developed

Better than satisfactory

Failed to meet

Purposeful and insightful selection of objectives suitable for

the specified age group and game category

Highly appropriate introduction \& related warm-up with high energy activity, maximum student participation

- Lesson focus is integral and highly appropriate to game category

\section{Modifications}

progress meaningfully and align closely with lesson purpose

Effective questioning and feedback links thoughtfully to lesson concept/tactical focus

- Purposeful selection of objectives suitable for the specified age group and game category

- Appropriate

introduction \& suitable warm-up with high energy activity \& full student

participation

- Lesson focus is highly appropriate to game category

- Modifications are relevant and link to lesson purpose

- Suitable introduction Questioning and feedback is significant and links to lesson concept/ tactical focus
Appropriate selection of objectives suitable for the specified age group and game category \& warm-up with active participation

Satisfactory selection of objectives generally suitable for the specified age group and game category

- Satisfactory introduction \& warm-up to commence lesson

Lesson focus is very appropriate to game category

- Modifications mostly link to lesson purpose

- Questioning and feedback usually links to lesson concept/ tactical focus

Lesson focus is appropriate to game category

linked to lesson purpose but change rather than progress

- Questioning and feedback is general

Satisfactory

requirements

Objectives are inappropriate for the specified age group and/or game category; or are missing from plan; and/or ...

- Introduction \& warm-up are unsuitable; and do not use time effectively

- Lesson focus is vague or does not link to game category

- Modifications are not scaffolded or relevant; and/or do not link to the lesson purpose and may link tactical focus/lesson concepts

Questioning and feedback is not specific; not focused on any particular concepts or tactical 


\section{Your micro teach will \\ be assessed on your}

ability and capacity to:

Demonstrate the ability to design appropriate activities

to achieve your

outcomes and

objectives for the

lesson

5 marks

\section{emonstrates the utilisation of \\ appropriate \\ instructional \\ techniques and style: \\ *Use of voice \& \\ vocabulary;}

o

- Prov

meaningful and

significant

progression of

worthwhile activities

to enable students to

achieve learning goals

- Equipment

organisation \& set-up is clear and detailed;

and maximises

student learning time and safety

- Promotes active engagement in physical activities and encourages students to critically reflect and discuss their understanding of the lesson focus and their performance

- Demonstrates highly effective instructional and communication strategies in

demonstrations; start/ stop signals; loud and clear \& enthusiastic

\section{Well-developed}

Better than satisfactory

- Provides a

thoughtful and

appropriate

progression of

worthwhile

modified activities

to enable student

learning

Equipment organisation \& setup is clear and makes good use of student learning

time and safety

- Provides

opportunities for students to practise key skills \& tactics

- Encourages

students to think

critically about the

lesson focus identified

Demonstrates mostly effective instructional and communication strategies in demonstrations; start/stop signals;
- Provides an

appropriate progression of modified activities which are logical in terms of skill/concept

- Safe and generally sound organisation of time, space and equipment

- Provides a variety of physical activities relevant to the focus of the lesson

- Provides

opportunities for students to think about the lesson focus identified

- Demonstrates somewhat effective instructional and communication strategies in demonstrations, start/ stop signals; voice
Failed to meet requirements

- The progression of activities is not always sequential

- Equipment organisation \& setup is satisfactory but could make better use of time, space and equipment

- Provides a variety of physical activities relevant to the lesson - Provides minimal concept

- Provides limited opportunities for students to think critically about the lesson purpose

- Sequence of activities does not facilitate meaningful development of understanding and demonstration of skill/concept[s]

- Inefficient and ineffective use of time, equipment and space opportunities for students to practise key skills \& tactics

- Little or no apparent alignment between outcomes and activities

- Demonstrates basic instructional and communication strategies with occasional use of demonstrations \& start/stop signals; 
Appendix 2 (Continued)

\begin{tabular}{|c|c|c|c|c|c|}
\hline $\begin{array}{l}\text { Your micro teach will } \\
\text { be assessed on your } \\
\text { ability and capacity to: }\end{array}$ & Outstanding & Well-developed & Better than satisfactory & Satisfactory & $\begin{array}{c}\text { Failed to meet } \\
\text { requirements }\end{array}$ \\
\hline $\begin{array}{l}\text { *Delivery of } \\
\text { instructions; } \\
\text { *Teacher presence } \\
\\
5 \text { marks }\end{array}$ & $\begin{array}{l}\text { voice; an impressive } \\
\text { teacher presence; clear \& } \\
\text { concise appropriately } \\
\text { paced instructional cues } \\
\text { \& age-appropriate } \\
\text { language }\end{array}$ & $\begin{array}{l}\text { loud and clear \& } \\
\text { enthusiastic voice; an } \\
\text { engaging teacher } \\
\text { presence; clear \& } \\
\text { concise appropriately } \\
\text { paced instructional } \\
\text { cues \& age-appropriate } \\
\text { language }\end{array}$ & $\begin{array}{l}\text { usually heard; an } \\
\text { effective teacher } \\
\text { presence; usually clear \& } \\
\text { some appropriately } \\
\text { paced instructional cues } \\
\& \text { age-appropriate } \\
\text { language }\end{array}$ & $\begin{array}{l}\text { voice is usually heard; } \\
\text { a satisfactory teacher } \\
\text { presence; cues may be } \\
\text { too long-winded; too } \\
\text { much talking; } \\
\text { sometimes unsuitable } \\
\text { age-appropriate } \\
\text { language or ineffective }\end{array}$ & $\begin{array}{l}\text { voice not heard } \\
\text { effectively; teacher } \\
\text { presence did not enable } \\
\text { effective learning; } \\
\text { poorly paced } \\
\text { instruction; language } \\
\text { not age-appropriate }\end{array}$ \\
\hline $\begin{array}{l}\text { Final Grade } \\
\text { Comment: }\end{array}$ & High Distinction & Distinction & Credit & Pass & Fail \\
\hline
\end{tabular}

